\title{
sciendo
}

\section{Variability of Technical Actions During Small-Sided Games in Young Soccer Players}

\author{
by \\ Filipe Manuel Clemente1,2, Hugo Sarmento ${ }^{3}$, Israel Teoldo Costa ${ }^{4}$, Ana Rita Enes ${ }^{1}$, \\ Ricardo Lima ${ }^{1}$
}

\begin{abstract}
The purpose of this study was three-fold: (i) to test the between-sessions variability of 3 vs. 3 and 6 vs. 6 formats in under-11 players, (ii) to assess the within-session variability of 3 vs. 3 and 6 vs. 6 formats, and (iii) to investigate the variations of technical actions between formats. Sixteen soccer players ( $10.1 \pm 0.3$ years old) participated in this study. Both formats of play were played twice within an interval of one week to test the between-session variability and the variables of conquered balls (CBs), received balls (RBs), lost balls (LBs), attacking balls/passes (ABs) and shots (Ss) were analyzed using the Performance Assessment in Team Sports instrument in all matches. Moderate variations on the sum of sets during the 3 vs. 3 and 6 vs. 6 formats were observed in all variables. Considering the variations of technical actions made between sets in the 3 vs. 3 format, likely moderate increases were found in set 2 vs. 1 in terms of RB (37.5\%, [-2.7;94.2]), and likely small decreases were found in set 3 vs. 2 for the same variable $(-18.3 \%$, [-37.8;7.3]). In the 6 vs. 6 format, only possibly small increases were found for set 3 vs. 1 in $S(22.5 \%,[-7.0 ; 61.3])$. Generally (sum of sets), the variables standardized per minute revealed almost certain very large decreases in the 6 vs. 6 vs. the 3 vs. 3 format in the variables of CB (-67.9\%, [-75.3;-55.9]), LB (-66.0\%, [-73.9;-55.7]), RB (-65.6\%, [-74.8;53.1]) and $S(-87.6 \%,[-93.1 ;-77.7])$. The results of this study suggest that both formats of play are too noisy to be reproducible. The 3 vs. 3 format largely increased the number of individual technical actions.
\end{abstract}

Key words: soccer, reproducibility, drill-based tasks, sports training.

\section{Introduction}

Small-sided games (SSGs) are often used during training to develop both the physical and technical performance of soccer players (Halouani et al., 2014; Kalinowski et al., 2019). These games are smaller, conditioned versions of the regular match, and they aim to prepare players for specific tactical contents and to increase intensity and individual participation (Clemente et al., 2015; Hill-Haas et al., 2011). Usually, SSGs use different task constraints such as the number of players involved (formats), the size and shape of the pitch, the aim of the match, the scoring method, ball touch limitations or other specific rules, to achieve the main purpose of the coach (Davids et al., 2013).

SSGs can be used in different contexts and competitive levels. However, the majority of previous research has focused on the effects in highly specialized athletes (Under-17, Under-19, or senior) and had the physiological and physical demands of these matches as their main priority (Aguiar et al., 2012; Clemente et al., 2014; Halouani et al., 2014). Despite the great importance of these matches for improving the fitness levels of players, tactical-technical

1 - Polytechnic Institute of Viana do Castelo, School of Sport and Leisure, Melgaço, Portugal.

2 - Instituto de Telecomunicações, Delegação da Covilhã, Portugal.

3 - Research Unit for Sport and Physical Activity (CIDAF), Faculty of Sport Sciences and Physical Education, University of Coimbra, Coimbra, Portugal

4 - Universidade Federal de Viçosa - Campus Viçosa, Departamento de Educação Física, Núcleo de Pesquisa e Estudos em Futebol (NUPEF), Brazil. 
performance should also be considered when different task constraints are used (Serra-Olivares et al., 2015). In fact, the main proposal of SSGs is to associate highly physical stimulation with the dynamics of soccer in reduced formats in real training matches, consisting of its technical actions and tactical behaviors (González-Víllora et al., 2015; González-Víllora et al., 2011).

Considering the effects of SSGs in terms of technical actions, it has been consistently found that an increase in the number of technical actions made individually by players occurs in smaller formats of the match (Almeida et al., 2013; Clemente et al., 2014; González-Víllora et al., 2017; Joo et al., 2016; Katis and Kellis, 2009). Moreover, smaller pitch dimensions also promote an increase in the number of passes, shots, and tackles (Almeida et al., 2013; Silva et al., 2011). When looking at the effects of ball touch limitations in SSGs, it was found that higher levels of possession of the ball occurred with one-touch limitations and that great success in passes and in the number of duels was observed with two ball touches allowed and under free play conditions (Dellal et al., 2011).

Despite the above-mentioned studies conducted on SSGs, to the best of knowledge, there is no information regarding the reliability of these matches to consistently promote similar participation of players in specific formats of play. In fact, the reproducibility of these matches should be considered at the moment of implementation and in the early stages of specialization. A high variability level may represent an inconsistency in technical stimuli for young players. Moreover, the effects of SSGs in youth players have not been properly researched, considering that few studies have analyzed tactical behaviors in under-11 players (Castelão et al., 2014; Oh and Joo, 2018; Silva et al., 2014) and that no studies have analyzed technical actions performed by youth players.

According to Sarmento et al. (2018), the actual challenge for researchers is to align these new measures with the needs of coaches through a more integrated relationship between coaches, practitioners and researchers, to produce practical and usable information that improves player's performance and coach activity. Considering the scarce research dedicated to the effects of SSGs in youth players and the nonexistent research testing the reproducibility of technical actions of these matches, the present study had three purposes: (i) to test the between-sessions variability of 3 vs. 3 and 6 vs. 6 formats in under-11 players; (ii) to assess the within-session variability of 3 vs. 3 and 6 vs. 6 formats, and (iii) to investigate variations in technical actions of 3 vs. 3 and 6 vs. 6 formats.

\section{Methods}

\section{Participants}

Sixteen youth soccer Portuguese players (10.1 \pm 0.3 years old; $4.4 \pm 2.0$ years of practice; $34.3 \pm 4.7 \mathrm{~kg} ; 143.6 \pm 7.1 \mathrm{~cm}$ ) participated in this study. The sample comprised 658 coded actions during the 3 vs. 3 and 443 during the 6 vs. 6 format. The participants and their parents were informed of the aim of the study and its design, as well as of the implications, risks, and benefits of participating. After giving their acceptance, the parents signed an informed consent form. This study followed the ethical standards for study in humans as outlined in the Declaration of Helsinki. Experimental approach

This repeated measures study was conducted during four consecutive weeks and aimed to analyze the variability of two SSGs formats ( 3 vs. 3 and 6 vs. 6 ) in order to reproduce technical actions executed by youth soccer players. These players trained three times a week and played matches on the weekends. The 3 vs. 3 and 6 vs. 6 formats were repeated within a period of exactly one week. The first two sessions were used to test the 3 vs. 3 format, and the last two sessions were used to test the 6 vs. 6 format. Each session was conducted during the middle of the week, 48 hours after the last high-load session. The sessions occurred at 6:00 p.m. at an average temperature of $15^{\circ} \mathrm{C}$ and with no rain. The same players acted on the same balanced teams (based on the recommendations of the head coach and on the playing positions) to maintain the same conditions between repeated measures. The matches were recorded by two digital cameras, and technical actions were compared between sessions, sets, and formats.

\section{Small-sided games}

The 3 vs. 3 and 6 vs. 6 formats were played on synthetic turf with dimensions of $15 \mathrm{x}$ $20 \mathrm{~m}\left(50 \mathrm{~m}^{2}\right.$ per player $)$ and $30 \times 22 \mathrm{~m}\left(55 \mathrm{~m}^{2}\right.$ per player), respectively. These individual playing areas followed the small pitch dimensions 
suggested in a previous review on the topic (Little, 2009). Both formats involved a small goal $(2 \times 1 \mathrm{~m})$ in the middle of the endline. The regimen of the 3 vs. 3 format was three sets of 3 min with 2 min rest intervals between sets. With regard to the 6 vs. 6 format, three sets of $6 \mathrm{~min}$ were implemented, with $2 \mathrm{~min}$ rest intervals between sets. Players were familiarized with the formats before the sessions. The sessions were initialized with a standard warm-up protocol consisting of $5 \mathrm{~min}$ of jogging, $5 \mathrm{~min}$ of dynamic stretching and mobility and $5 \mathrm{~min}$ of sprints, accelerations, and decelerations.

\section{Technical actions}

The matches were recorded on two planes (one at an open angle and the other focusing on the player with the ball) using two digital cameras (Go Pro Hero 2, 1280 x 960, $25 \mathrm{~Hz}$ ). After recording the matches, the notification was executed for the technical actions made by each player considering conquered balls (CBs), received balls (RBs), lost balls (LBs), attacking balls/passes (ABs), and shots (Ss). The notification followed the recommendations of the instrument Performance Assessment in Team Sports (Gréhaigne et al., 1997). A CB was considered when a player stole the ball from an opponent or recaptured it after an unsuccessful shot. An RB was considered when a player received the ball from a teammate and did not immediately lose control of it. An LB was considered when a player lost possession of the ball to the other team without having scored a goal. An $\mathrm{AB}$ was considered when a pass to a teammate was made with an attempt to move forward and to put pressure on the other team. A S was considered when the players tried to score by means of a shot, including both successful and unsuccessful shots. In all variables, except for Ss, only the executed actions (succeeded actions) were coded.

The observations and notifications were executed by the same observer, who had more than 3 years of experience in match analysis. The observer was tested for his reliability level. Ten percent of the full data was analyzed twice, interspaced by a period of 20 days. An intra-class correlation of 0.85 was achieved, what ensured good reliability of the analysis.

\section{Statistical procedures}

Results were presented in the form of text, tables, and figures as either means with standard deviation (SD) or means with a $90 \%$ confidence interval $(90 \%$ CI $)$ when specified. Betweensessions variability of technical actions in each set and their accumulated values derived from all sets were analyzed by computing typical errors of measurement, expressed as the coefficient of variation $(\mathrm{CV})$ or as standardized units (STE), using a specifically-designed Excel spreadsheet (Hopkins, 2015). To examine the within-session variations, differences between sets were analyzed using standardized differences of effect size (ES) with a 90\% CI (Cohen, 1988). The following interpretation of ES was used (Batterham and Hopkins, 2006): $<0.2=$ trivial; 0.2$0.6=$ small; $0.6-1.2=$ moderate; $>1.2=$ large. Probabilities were calculated considering the smallest worthwhile changes (SWC, $0.2 \times$ between-subjects SD) (Hopkins et al., 2009). Qualitative probabilistic mechanistic inferences about the true effects were made using these probabilities (Hopkins et al., 2009). The scale for qualitative probabilities was as follows: $25-75 \%=$ possible; $75-95 \%$ = likely; $95-99 \%$ = very likely; $>99 \%=$ almost certain (Hopkins et al., 2009).

\section{Results}

Moderate variations on the sum of sets during the 3 vs. 3 format between sessions were observed in the variables of RBs (Coefficient of Variation, CV, 26.4 [90\% Confidence Interval, [18.6;47.1]; Standardized Typical Error, STE, 0.99 [0.72;1.62]), CBs (CV, 107.5 [70.3;232.4]; STE, 1.17 [0.85;1.92]), LBs (CV, 50.6 [34.8;96.1]; STE, 0.87 [0.63;1.43]), ABs (CV, 79.6 [53.3;162.0]; ETS, 0.79 [0.58;1.31]) and Ss (CV, 62.2 [42.3;121.6]; ETS, 0.94 [0.68;1.54]). Variability of the results of sets between sessions can be found in Table 1 .

Moderate-to-large variations on the sum of sets during the 6 vs. 6 format between sessions were observed in the variables of RBs $(\mathrm{CV}, 52.2$ [35.9;99.6]; STE, 0.67 [0.49;1.11]), CBs (CV, 133.8 [85.8;304.5]; STE, 1.22 [0.89;2.00]), LBs (CV, 80.1 [53.6;163.3]; STE, 0.96 [0.70;1.59]), ABs (CV, 90.1 [59.8;187.8]; ETS, 0.77 [0.56;1.27]) and Ss (CV, 90.1 [59.8;187.8]; ETS, 0.48 [0.35;0.79]). Variability of the results of sets between sessions can be found in Table 2.

Considering the variations of technical actions made between sets in the 3 vs. 3 format, likely moderate increases of set 2 vs. 1 were found in $\mathrm{RBs}(37.5 \%,[-2.7 ; 94.2])$ and likely small 
decreases of set 3 vs. 2 for the same variable ($18.3 \%$, [-37.8;7.3]). Likely small increases of set 2 vs. 1 in Ss $(47.3 \%$, [-4.9;128.1]) as well as of set 3 vs. $1(38.4 \%$, $[-8.8 ; 110.0])$ were found. In the 6 vs. 6 format, only possibly small increases of set 3 vs. 1 in Ss $(22.5 \%,[-7.0 ; 61.3])$ were observed. The remaining results were unclear. The standardized differences (Cohen) and probabilities for all variables and both formats can be found in Figures 1 - 3 .
Generally (sum of sets), the variables standardized per minute revealed almost certain very large decreases of the 6 vs. 6 vs. 3 vs. 3 format in the variables of CBs $(-67.9 \%$, [-75.3;$55.9])$, LBs (-66.0\%, [-73.9;-55.7]), RBs (-65.6\%, [74.8;-53.1]) and Ss (-87.6\%, [-93.1;-77.7]). Likely moderate decreases of the $6 \times 6$ vs. $3 \times 3$ format in ABs $(-50.8 \%$, [-78.1;10.6]) were found. The standardized differences (Cohen) and probabilities for all sets are presented in Figure 4.

\begin{tabular}{|c|c|c|c|c|c|c|c|c|}
\hline \multicolumn{9}{|c|}{$\begin{array}{r}\text { Table } 1 \\
\text { Variability of technical actions between sessions during the } 3 \text { vs. } 3 \text { format. }\end{array}$} \\
\hline \multirow[t]{2}{*}{ Set } & \multirow[t]{2}{*}{ Variable } & \multirow{2}{*}{$\begin{array}{l}\mathrm{M}(\mathrm{SD}) \\
\text { Session } \\
\quad 1\end{array}$} & \multirow{2}{*}{$\begin{array}{l}\mathrm{M}(\mathrm{SD}) \\
\text { Session } \\
\quad 2\end{array}$} & \multicolumn{2}{|c|}{ Typical error (CV) } & \multicolumn{2}{|c|}{$\begin{array}{l}\text { Standardized } \\
\text { typical error }\end{array}$} & \multirow[t]{2}{*}{ Magnitude } \\
\hline & & & & Value & {$[90 \% \mathrm{CI}]$} & Value & $90 \% \mathrm{CI}$ & \\
\hline \multirow{5}{*}{1} & RB (n) & $3.5(1.8)$ & $4.0(1.8)$ & 73.4 & {$[49.4 ; 147.4]$} & 0.90 & {$[0.66 ; 1.48]$} & Moderate \\
\hline & CB (n) & $2.0(1.1)$ & $2.0(0.9)$ & 60.3 & {$[41.1 ; 117.4]$} & 0.94 & {$[0.68 ; 1.54]$} & Moderate \\
\hline & LB (n) & $2.0(0.8)$ & $1.7(1.1)$ & 56.6 & {$[38.7 ; 109.1]$} & 0.90 & {$[0.66 ; 1.48]$} & Moderate \\
\hline & $\mathrm{AB}(\mathrm{n})$ & $1.3(0.7)$ & $1.3(0.5)$ & 20.7 & {$[14.7 ; 36.3]$} & 0.52 & {$[0.38 ; 0.85]$} & Small \\
\hline & $S(n)$ & $1.6(0.7)$ & $2.3(1.3)$ & 63.8 & {$[43.3 ; 125.1]$} & 0.94 & {$[0.68 ; 1.54]$} & Moderate \\
\hline \multirow{5}{*}{2} & $\mathrm{RB}(\mathrm{n})$ & $5.0(1.6)$ & $5.0(2.3)$ & 53.1 & {$[36.5 ; 101.6]$} & 0.92 & {$[0.67 ; 1.52]$} & Moderate \\
\hline & CB (n) & $2.2(1.9)$ & $1.9(1.2)$ & 104.4 & {$[68.4 ; 224.1]$} & 1.10 & {$[0.80 ; 1.81]$} & Moderate \\
\hline & LB (n) & $1.7(0.9)$ & $1.7(0.7)$ & 71.1 & {$[48.0 ; 142.0]$} & 1.13 & {$[0.83 ; 1.87]$} & Moderate \\
\hline & $\mathrm{AB}(\mathrm{n})$ & $2.0(1.5)$ & $1.4(1.0)$ & 44.6 & {$[30.8 ; 83.4]$} & 0.65 & {$[0.47 ; 1.06]$} & Moderate \\
\hline & $\mathrm{S}(\mathrm{n})$ & $2.5(1.1)$ & $2.4(1.3)$ & 62.5 & {$[42.5 ; 122.3]$} & 0.95 & {$[0.70 ; 1.57]$} & Moderate \\
\hline \multirow{5}{*}{3} & $\mathrm{RB}(\mathrm{n})$ & $3.8(1.8)$ & $4.6(2.5)$ & 74.6 & {$[50.2 ; 150.2]$} & 0.94 & {$[0.68 ; 1.54]$} & Moderate \\
\hline & $\mathrm{CB}(\mathrm{n})$ & $2.1(1.4)$ & $2.1(0.9)$ & 85.6 & {$[57.0 ; 176.5]$} & 1.14 & {$[0.83 ; 1.88]$} & Moderate \\
\hline & LB (n) & $1.8(1.3)$ & $1.9(1.3)$ & 76.4 & {$[51.3 ; 154.4]$} & 0.98 & {$[0.72 ; 1.61]$} & Moderate \\
\hline & $\mathrm{AB}(\mathrm{n})$ & $1.3(0.5)$ & $1.5(1.1)$ & 65.4 & {$[44.3 ; 128.8]$} & 1.14 & {$[0.83 ; 1.87]$} & Moderate \\
\hline & $\mathrm{S}(\mathrm{n})$ & $2.3(1.6)$ & 2.4(1.6) & 88.7 & {$[58.9 ; 184.1]$} & 1.02 & {$[0.74 ; 1.67]$} & Moderate \\
\hline \multirow{5}{*}{$\begin{array}{l}\text { Sum of } \\
\text { all sets }\end{array}$} & $\mathrm{RB}(\mathrm{n})$ & $12.3(2.9)$ & $13.6(3.3)$ & 26.4 & {$[18.6 ; 47.1]$} & 0.99 & {$[0.72 ; 1.62]$} & Moderate \\
\hline & $\mathrm{CB}(\mathrm{n})$ & $5.8(3.4)$ & $5.6(2.1)$ & 107.5 & {$[70.3 ; 232.4]$} & 1.17 & {$[0.85 ; 1.92]$} & Moderate \\
\hline & LB (n) & $4.9(2.2)$ & $4.7(2.5)$ & 50.6 & {$[34.8 ; 96.1]$} & 0.87 & {$[0.63 ; 1.43]$} & Moderate \\
\hline & $\mathrm{AB}(\mathrm{n})$ & $3.6(2.5)$ & $3.1(2.5)$ & 79.6 & {$[53.3 ; 162.0]$} & 0.79 & {$[0.58 ; 1.31]$} & Moderate \\
\hline & S (n) & $5.8(2.3)$ & $6.6(3.3)$ & 62.2 & {$[42.3 ; 121.6]$} & 0.94 & {$[0.68 ; 1.54]$} & Moderate \\
\hline \multicolumn{9}{|c|}{$\begin{array}{c}\text { RB: received balls; CB: conquered balls; LB: lost balls; AB: attacking balls; S: shots; } n: \\
\text { number; CV: coefficient of variation (\%); } 90 \% \text { CI: confidence interval of } 90 \% ; \text { M: mean; } \\
\text { SD: standard deviation }\end{array}$} \\
\hline
\end{tabular}


Table 2

Variability of technical actions between sessions during the 6 vs. 6 format.

\begin{tabular}{|c|c|c|c|c|c|c|c|c|}
\hline \multirow{2}{*}{ Set } & \multirow{2}{*}{ Variable } & \multirow{2}{*}{$\begin{array}{c}\mathrm{M}(\mathrm{SD}) \\
\text { Session } \\
1\end{array}$} & \multirow{2}{*}{$\begin{array}{c}M(S D) \\
\text { Session } \\
2\end{array}$} & \multicolumn{2}{|c|}{ Typical error (CV) } & \multicolumn{2}{|c|}{$\begin{array}{l}\text { Standardized } \\
\text { typical error }\end{array}$} & \multirow{2}{*}{ Magnitude } \\
\hline & & & & Value & {$[90 \% \mathrm{CI}]$} & Value & $90 \% \mathrm{CI}$ & \\
\hline \multirow{5}{*}{1} & $\mathrm{RB}(\mathrm{n})$ & $3.0(2.1)$ & $2.9(1.3)$ & 71.7 & {$[48.3 ; 143.4]$} & 0.80 & {$[0.59 ; 1.32]$} & Moderate \\
\hline & $\mathrm{CB}(\mathrm{n})$ & $2.2(1.5)$ & $1.3(0.7)$ & 59.9 & {$[40.8 ; 116.4]$} & 0.85 & {$[0.62 ; 1.41]$} & Moderate \\
\hline & LB (n) & $1.9(1.6)$ & $1.1(0.3)$ & 56.5 & {$[38.7 ; 109.0]$} & 0.95 & {$[0.69 ; 1.57]$} & Moderate \\
\hline & $\mathrm{AB}(\mathrm{n})$ & $1.4(0.7)$ & $1.6(1.0)$ & 55.5 & {$[38.0 ; 106.8]$} & 0.97 & {$[0.71 ; 1.60]$} & Moderate \\
\hline & $\mathrm{S}(\mathrm{n})$ & $1.3(0.9)$ & $1.2(0.4)$ & 49.2 & {$[33.9 ; 93.2]$} & 1.07 & {$[0.78 ; 1.77]$} & Moderate \\
\hline \multirow{5}{*}{2} & $\mathrm{RB}(\mathrm{n})$ & $3.5(2.1)$ & $3.0(1.4)$ & 75.9 & {$[51.0 ; 153.2]$} & 1.19 & {$[0.86 ; 1.95]$} & Moderate \\
\hline & $\mathrm{CB}(\mathrm{n})$ & $1.8(1.3)$ & $1.4(0.8)$ & 85.0 & {$[56.6 ; 175.1]$} & 1.17 & {$[0.85 ; 1.92]$} & Moderate \\
\hline & $\mathrm{LB}(\mathrm{n})$ & $1.6(0.7)$ & $1.4(0.5)$ & 33.3 & {$[23.3 ; 60.4]$} & 0.73 & {$[0.53 ; 1.20]$} & Moderate \\
\hline & $\mathrm{AB}(\mathrm{n})$ & $2.1(1.4)$ & $1.4(1.0)$ & 45.2 & {$[31.2 ; 84.7]$} & 0.67 & {$[0.49 ; 1.10]$} & Moderate \\
\hline & $\mathrm{S}(\mathrm{n})$ & $1.3(0.7)$ & $1.0(0.0)$ & 31.7 & {$[22.3 ; 57.3]$} & 1.00 & {$[0.73 ; 1.65]$} & Moderate \\
\hline \multirow{5}{*}{3} & $\mathrm{RB}(\mathrm{n})$ & $3.3(2.2)$ & 3.7(1.9) & 38.9 & {$[27.1 ; 71.8]$} & 0.52 & {$[0.38 ; 0.85]$} & Moderate \\
\hline & $\mathrm{CB}(\mathrm{n})$ & $1.8(1.1)$ & $1.4(0.7)$ & 70.6 & {$[47.7 ; 140.9]$} & 1.06 & {$[0.78 ; 1.75]$} & Moderate \\
\hline & $\mathrm{LB}(\mathrm{n})$ & $1.4(0.7)$ & $1.2(0.4)$ & 40.1 & {$[27.9 ; 74.2]$} & 0.94 & {$[0.69 ; 1.55]$} & Moderate \\
\hline & $\mathrm{AB}(\mathrm{n})$ & $1.1(0.3)$ & $1.8(1.4)$ & 65.0 & {$[44.1 ; 128.0]$} & 1.06 & {$[0.78 ; 1.75]$} & Moderate \\
\hline & $S(n)$ & $1.5(0.8)$ & $1.2(0.4)$ & 40.8 & {$[28.3 ; 75.5]$} & 0.86 & {$[0.63 ; 1.42]$} & Moderate \\
\hline \multirow{5}{*}{$\begin{array}{l}\text { Sum } \\
\text { of all } \\
\text { sets }\end{array}$} & $\mathrm{RB}(\mathrm{n})$ & $9.7(4.2)$ & $9.4(3.6)$ & 52.2 & [35.9;99.6] & 0.67 & {$[0.49 ; 1.11]$} & Moderate \\
\hline & $\mathrm{CB}(\mathrm{n})$ & $4.9(2.6)$ & $2.8(2.0)$ & 133.8 & [85.8;304.5] & 1.22 & {$[0.89 ; 2.00]$} & Large \\
\hline & LB (n) & $4.2(2.0)$ & $2.4(1.1)$ & 80.1 & {$[53.6 ; 163.3]$} & 0.96 & {$[0.70 ; 1.59]$} & Moderate \\
\hline & $\mathrm{AB}(\mathrm{n})$ & $3.8(2.6)$ & $3.8(2.6)$ & 90.1 & {$[59.8 ; 187.8]$} & 0.77 & {$[0.56 ; 1.27]$} & Moderate \\
\hline & $S(n)$ & $2.6(2.4)$ & $1.9(1.3)$ & 40.6 & {$[28.2 ; 75.2]$} & 0.48 & {$[0.35 ; 0.79]$} & Moderate \\
\hline
\end{tabular}

RB: received balls; CB: conquered balls; LB: lost balls; AB: attacking balls; S: shots; $n$ : number; CV: coefficient of variation (\%); $90 \%$ CI: confidence interval of $90 \%$; M: mean; $S D$ : standard deviation 
(a)

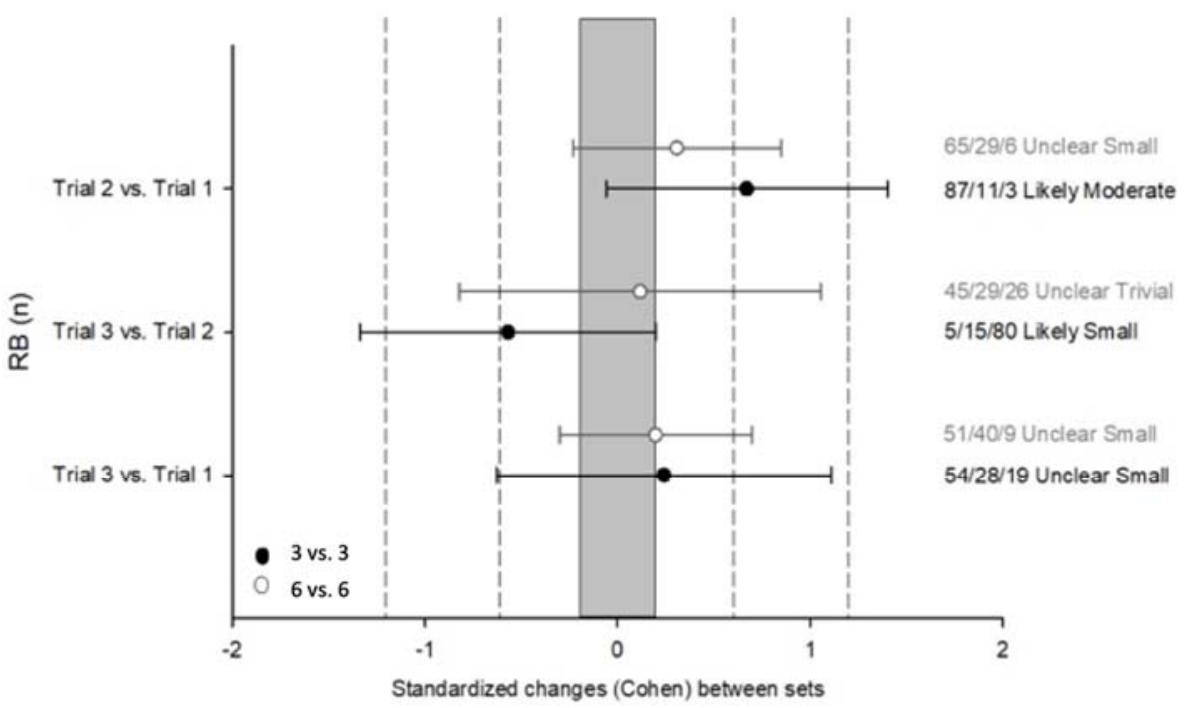

(b)

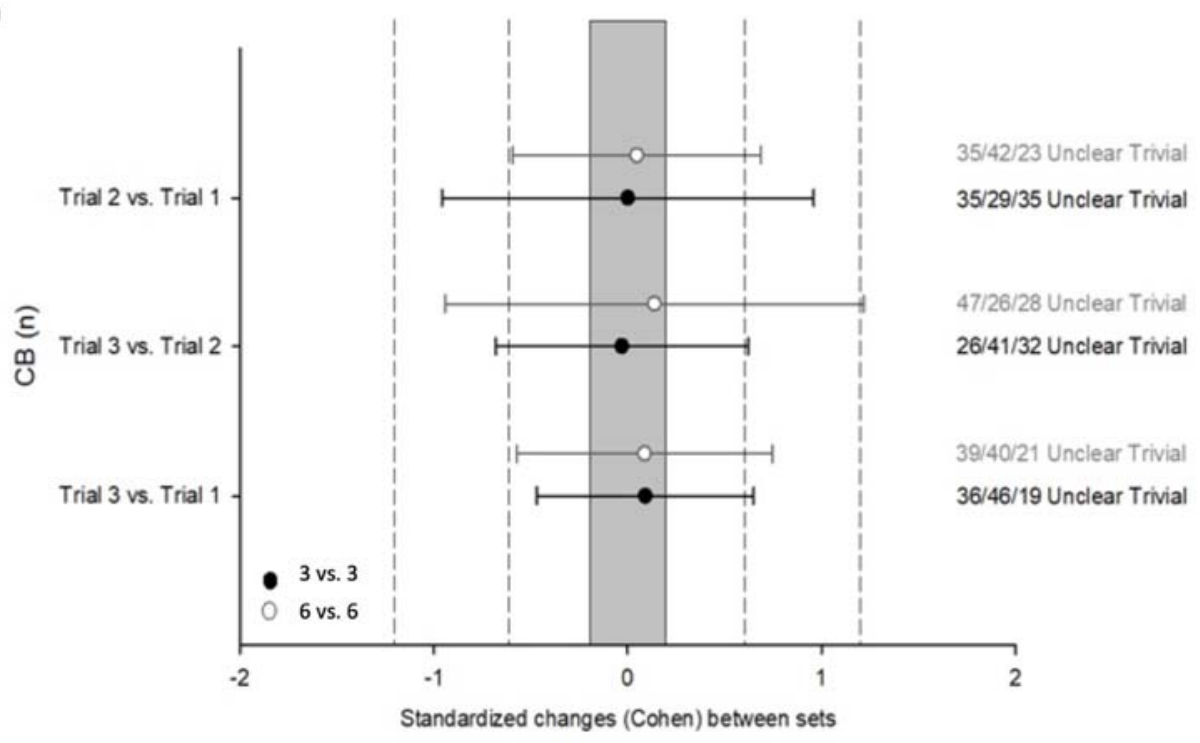

\section{Figure 1}

Standardized difference (Cohen) between individual sets in (a) received balls; $(b)$ conquered balls during 3 vs. 3 and 6 vs. 6 formats. The grey area represents trivial magnitude. Standardized value direction depends on the relationship $A-B$. 
(a)

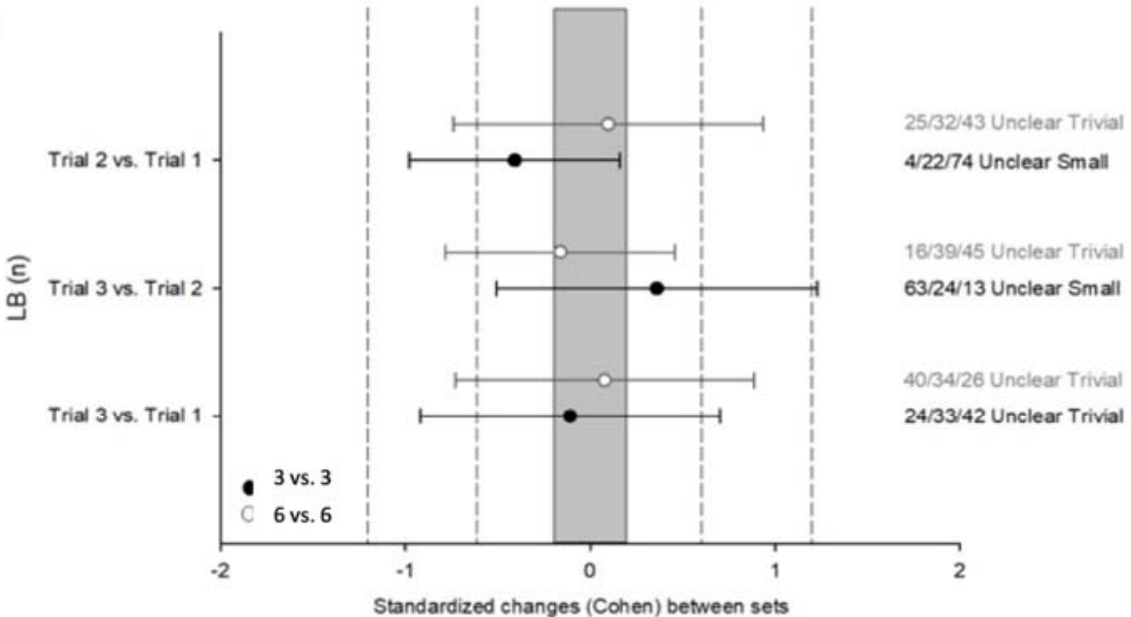

(b)

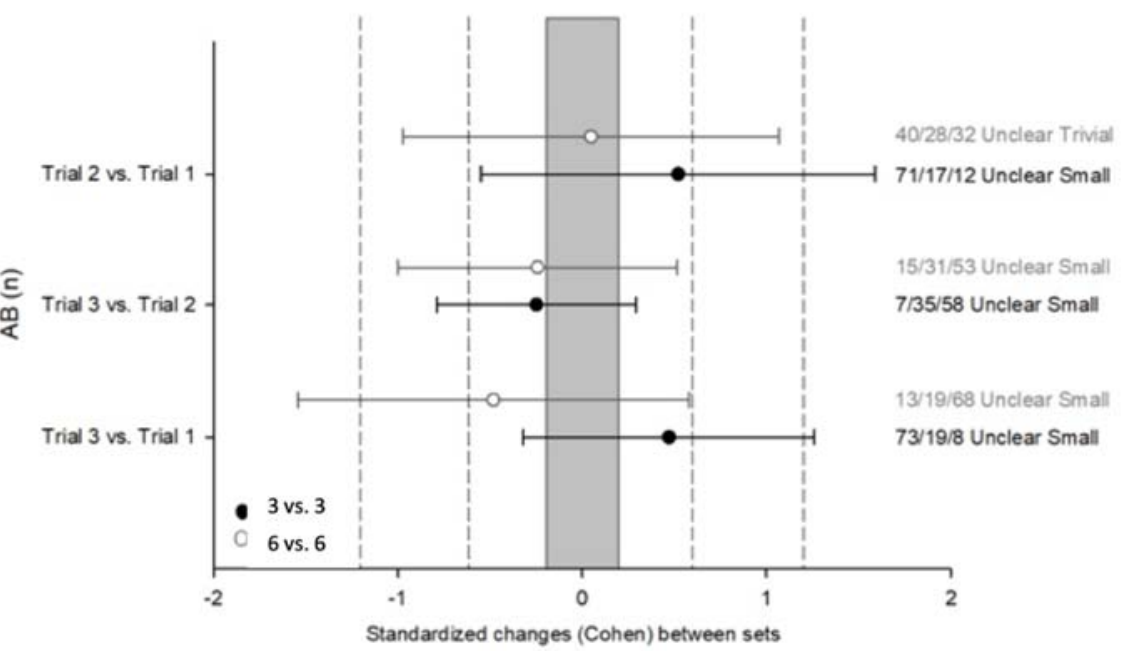

Figure 2

Standardized difference (Cohen) between individual sets in (a) lost balls; (b) attacking balls during 3 vs. 3 and 6 vs. 6 formats. The grey area represents trivial magnitude. Standardized value direction depends on the relationship A-B. 


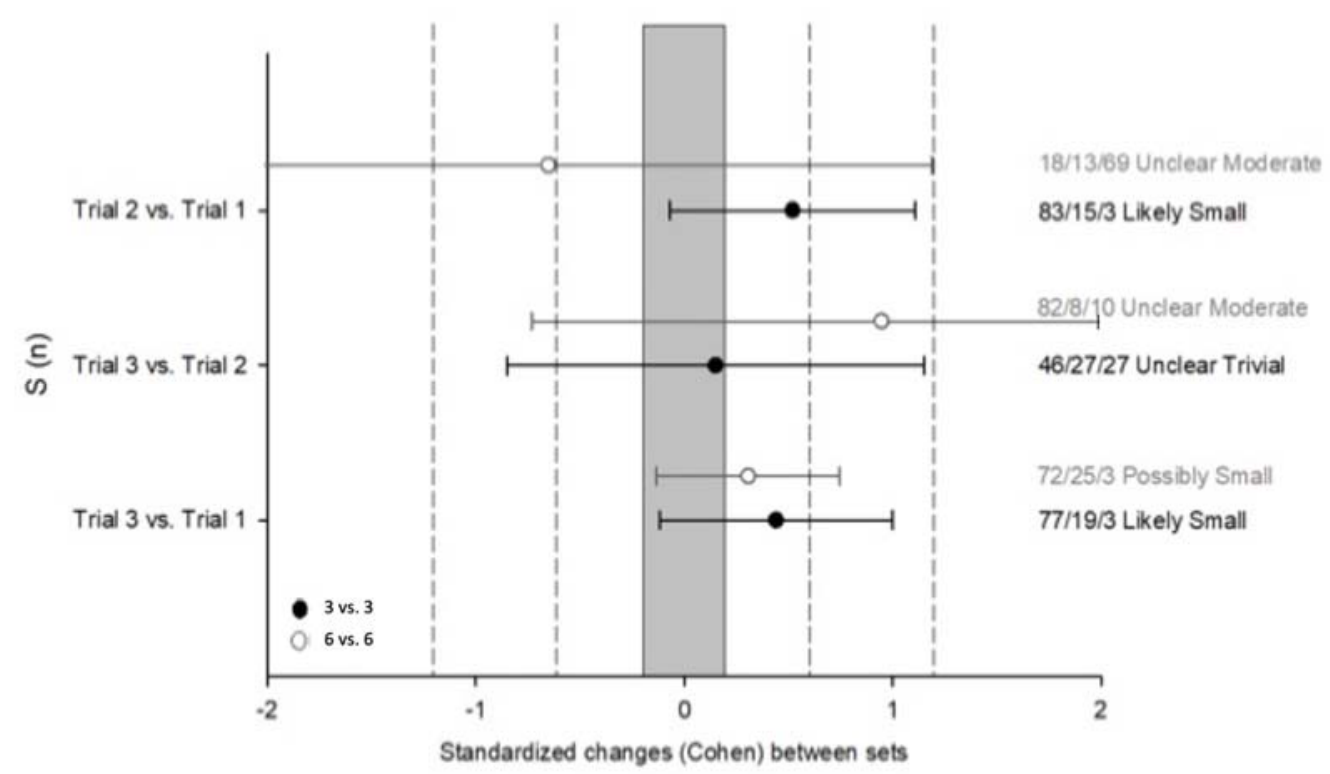

Figure 3

Standardized difference (Cohen) between individual sets in (a) shots during 3 vs. 3 and 6 vs. 6 formats. The grey area represents trivial magnitude. Standardized value direction depends on the relationship A-B.
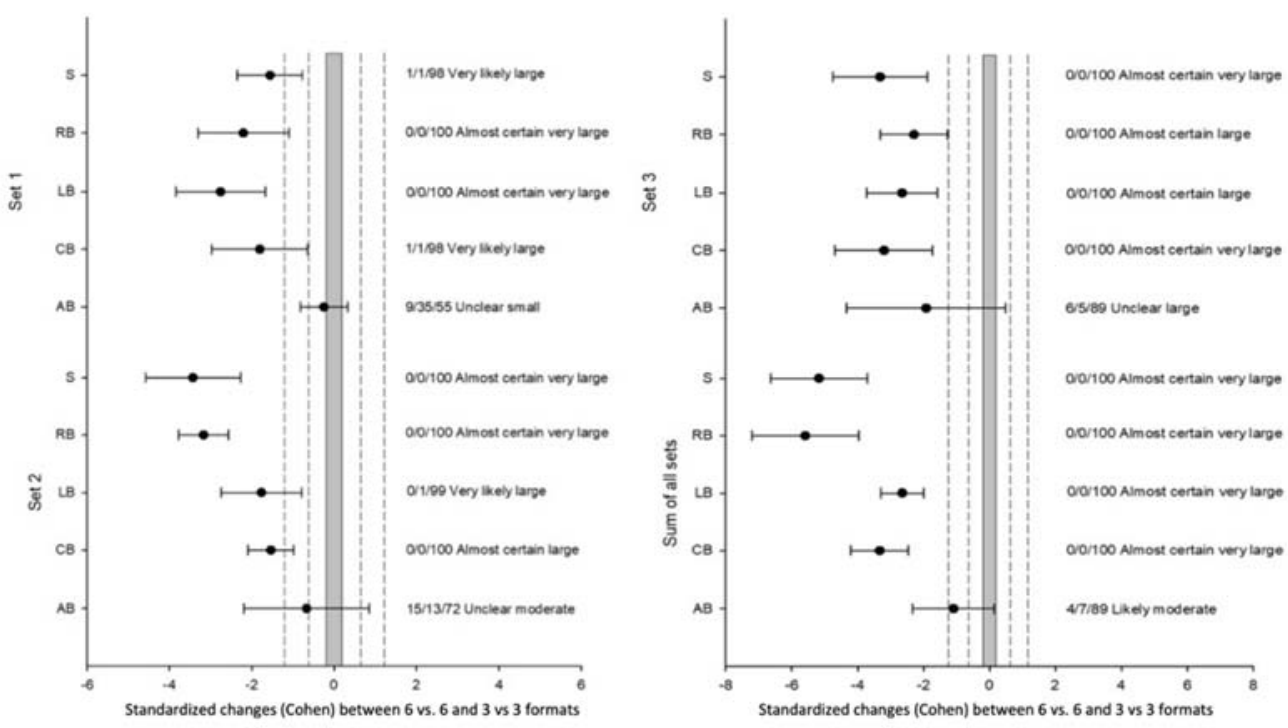

Figure 4

Standardized difference (Cohen) between formats in $(R B)$ received balls; $(C B)$ conquered balls; (LB) lost balls; (AB) attacking balls; (S) shots standardized per minute across sets. The grey area represents trivial magnitude. Standardized value direction depends on the relationship 6 vs. 6 - 3 vs. 3 . 


\section{Discussion}

This study was the first that has tested the reliability of SSGs to reproduce technical actions in youth players. For such an age group, it is important to ensure that players are given the appropriate stimuli, so they can acquire the skills of the sport. For this reason, coaches must ensure levels of technical demands similar to the levels of physical demands during the proposed training tasks (Williams and Hodges, 2005). Our results do not allow confidence regarding the reproducibility of technical actions performed during both the 3 vs. 3 and 6 vs. 6 formats. Overall, high coefficient of variation levels were observed for received balls $(52.2 \%)$, conquered balls $(133.8 \%)$, lost balls $(80.1 \%)$, attacking balls $(90.1 \%)$, and shots (90.1\%). All variables were moderate in terms of standardized typical error during the 3 vs. 3 format. In the 6 vs. 6 format, high coefficient of variation levels were also found for received balls $(26.4 \%)$, conquered balls (107.5\%), lost balls (50.6\%), attacking balls (79.6\%), and shots $(62.2 \%)$. All variables were moderate in terms of standardized typical error.

These findings are in line with previous studies that tested the reproducibility of physiological and physical variables of SSGs in professional and amateur players (Hill-Haas et al., 2008a, b; Rampinini et al., 2007; Stevens et al., 2016). From a physiological point-of-view, one study in amateur players found that blood lactate varied between 10.4 and $43.7 \%$ and that perceived exertion varied between 5.5 and $31.9 \%$ using heart rate as the unique reproducible variable (2.0-5.4\%) (Rampinini et al., 2007). Studies which used 2 vs. 2 and 4 vs. 4 formats in youth players also confirmed such tendencies (Hill-Haas et al., 2008a, b). Regarding the reproducibility of time-motion variables in 2 vs. 2, 4 vs. 4 and 6 vs. 6 formats, good reproducibility was found for low-intensity activities, such as total distance and walking distance. However, moderate-to-high-intensity activities were too noisy (Hill-Haas et al., 2008a, b). Similar evidence was found in the $6 \times 6$ format, which showed reproducibility for total distance and metabolic power and higher variability for moderate-to-high-intensity activities (Stevens et al., 2016).

Based on these findings, it is possible to discuss the applicability of SSGs to be a proper stimulus for technical actions. In fact, coaches must consider tactical behaviors and technical actions associated with the dynamics of SSGs rather than viewing SSGs as a training task to acquire or exercise a given skill. An approach that mixes more constrained training tasks to standardize technical stimuli with SSG scenarios can be a good solution for the progressive evolution of youth players. Moreover, coaches may also use specific task constraints to increase the standardization of these matches to reproduce technical actions (Davids et al., 2013). In fact, the aim of SSGs is to repeat without repetition (Tan et al., 2012), and for that reason, it seems worthwhile to increase the reproducibility of actions by maintaining the proper dynamics of the match during training.

The second objective of this study was to test the variability of technical actions between sets. Most of the comparisons between sets revealed unclear small differences in terms of technical actions. Thus, results were similar during the three sets in both the 3 vs. 3 and 6 vs. 6 formats. However, in the 3 vs. 3 format, likely moderate increases were found for set 2 vs. 1 for the variables of received balls (37.5\%), and likely small decreases for set 3 vs. 2 for the same variable (-18.3\%). Moreover, likely small increases for set 2 vs. $1(47.3 \%)$, as well as for set 3 vs. 1 $(38.4 \%)$ were found for shots. The differences detected in the 3 vs. 3 format show that in the second and third sets the volume of received balls and shots presented slightly-to-moderately increases. With regard to the 6 vs. 6 format, only possibly small increases for set 3 vs. 1 were found for shots $(22.5 \%,[-7.0 ; 61.3])$. These results may suggest that the 6 vs. 6 format is more stable in terms of the conditions of stimulation between sets and that the 3 vs. 3 format tends to increase the number of received balls and shots across the sets. This slight tendency found in youth players was in opposition to a previous study conducted on twenty international soccer players which found small decreases across the bouts in terms of the number of duels and the total number of ball possessions (Dellal et al., 2011). In the same way, a previous study conducted on senior players also revealed that successful passes and total passes decreased in bout 3 (Fanchini et al., 2011). The differences between the results found in the present study and previous research cited here could be due to the fact that senior players have 
great technical capacity and know-how. Thus, they enter the match with the maximal perception of how to act; for youth players, matches are still part of a learning process, as players are still coming to understand the dynamics of the game and how to act and to be prominent (Müller et al., 2018).

The final propose of this study was to test the variations of technical actions between the 3 vs. 3 and 6 vs. 6 formats. Considering the sum of all sets, the variables standardized per minute revealed almost certain very large decreases for the 6 vs. 6 vs. the 3 vs. 3 format for the variables of conquered balls $(-67.9 \%)$, lost balls $(-66.0 \%)$, received balls $(-65.6 \%)$, and shots $(-87.6 \%)$. Moreover, likely moderate decreases for the 6 vs. 6 vs. the 3 vs. 3 format were found for attacking balls $(-50.8 \%)$. The results reveal that the 3 vs. 3 format greatly increases individual participation of players during the match in comparison to larger formats (Aslan, 2013).

These results are in line with previous studies that tested smaller versus bigger SSGs (Almeida et al., 2013; Clemente et al., 2014; Joo et al., 2016; Katis and Kellis, 2009; Owen et al., 2014; Silva et al., 2014). In fact, individual participation and the volume of technical actions increase in smaller formats. Thus, they are appropriate to potentiate the activity of youth players and to reduce the complexity and heterogeneity of participation during the matches. The 3 vs. 3 format is perhaps less structured than the 6 vs. 6 format in terms of the tactical approach to the match, thus allowing each player to assume more than only one role (i.e., defender or attacker) and to participate in all moments of the match (Clemente et al., 2014). This is in line with previous findings that revealed a tendency of players to be more conservative in the 6 vs. 6 and aggressive in the 3 vs. 3 format, probably based on the space management and the fewer interactions between teammates (Silva et al., 2014).

This study had some limitations. For one, the sample is small, and the inferences should be taken cautiously. Moreover, in the future, it will be useful to analyze tactical behavior of players crossing such variables with technical performance trying to understand the outcomes.

The results of this study are important for practice. Both formats revealed that SSGs in youth players were too noisy and very slowly reproducible in terms of technical actions. Based on this, coaches should be careful when applying SSGs as the main training task for the acquisition of specific skills. Possibly, these matches should be designed with more constrained tasks that would ensure an appropriate and more homogeneous stimulation of technical actions. As such, SSGs should use the dynamics of the match to test the application of technical and tactical skills in a complex environment. Moreover, the results of this study showed that, in the 3 vs. 3 format, it was important to be aware that higher frequencies of technical actions would occur in the second and third sets, with the first set being more adequate for adjusting the players' perception of the reality of the format. Finally, coaches should use smaller formats (in this case, 3 vs. 3) to greatly increase individual participation and the frequencies of technical actions of youth players during this stage of their evolution.

\section{Conclusions}

The present study revealed that the 3 vs. 3 and 6 vs. 6 formats had moderate variability in the between-session analysis regarding the technical actions performed by youth soccer players. Moreover, the within-session analysis revealed small variations in technical actions, suggesting that the second and third sets show increases in individual actions compared with the first set. Considering the analysis of variation between the 3 vs. 3 and 6 vs. 6 formats, likely-to-almost-certain larger values were found for individual technical actions executed during the smaller format. The results suggest that coaches must be aware of the moderate variability that occurs in these matches to properly stimulate the technical performance of youth players. Moreover, coaches should also consider that matches with fewer players clearly increase individual participation in terms of technical actions. 


\section{References}

Aguiar M, Botelho G, Lago C, Maças V, Sampaio J. A review on the effects of soccer small-sided games. J Hum Kinet, 2012; 33: 103-113

Almeida $\mathrm{CH}$, Ferreira AP, Volossovitch A. Offensive sequences in youth soccer: effects of experience and small-sided games. J Hum Kinet, 2013; 36: 97-106

Aslan A. Cardiovascular responses, perceived exertion and technical actions during small-sided recreational soccer: effects of pitch size and number of players. J Hum Kinet, 2013; 38: 95-105

Batterham AM, Hopkins WG. Making meaningful inferences about magnitudes. Int J Sport Phys Perfor, 2006; 1: $50-57$

Castelão D, Garganta J, Santos R, Teoldo I. Comparison of tactical behaviour and performance of youth soccer players in 3v3 and 5v5 small-sided games. Int J Perfor Anal Sport, 2014; 14: 801-813

Clemente FM, Martins FM, Mendes RS. Developing aerobic and anaerobic fitness using small-sided soccer games: Methodological proposals. Stren Cond J, 2014; 36: 76-87

Clemente FM, Martins FML, Mendes RS. How coaches use their knowledge to develop small-sided soccer games: A case study. South Afri J Res Sport, Phys Edu Recr, 2015; 37: 1-11

Clemente FM, Wong DP, Martins FML, Mendes RS. Acute effects of the number of players and scoring method on physiological, physical, and technical performance in small-sided soccer games. Res Sport Med, 2014; 22: 380-397

Cohen J. Statistical power analysis for the behavioral sciences. Hillsdale, NJ: Lawrence Erlbaum Associates; 1988

da Silva CD, Impellizzeri FM, Natali AJ, de Lima JR, Bara-Filho MG, Silami-Garçia E, Marins JC. Exercise intensity and technical demands of small-sided games in young brazilian soccer players: effect of number of players, maturation, and reliability. J Streng Cond Res, 2011; 25: 2746-2751

Davids K, Araújo D, Correia V, Vilar L. How small-sided and conditioned games enhance acquisition of movement and decision-making skills. Exer Sport Sci Rev, 2013; 41: 154-161

Dellal A, Lago-Penas C, Wong DP, Chamari K. Effect of the number of ball contacts within bouts of 4 vs. 4 small-sided soccer games. Int J Sport Phys Perfor, 2011; 6: 322-333

Fanchini M, Azzalin A, Castagna C, Schena F, McCall A, Impellizzeri FM. Effect of bout duration on exercise intensity and technical performance of small-sided games in soccer. J Streng Cond Res, 2011; 25: 453-458

González-Víllora S, Clemente FM, Martins FML, Pastor-Vicedo JC. Effects of regular and conditioned smallsided games on young football players' heart rate responses, technical performance and network structure. Hum Mov, 2017; 18: 135-145

González-Víllora S, García-López LM, Contreras-Jórdan OR. Decision making and skill development in youth football players. Rev Int Med Cie Act Fis Dep, 2015; 15: 467-487

González-Víllora S, García-López LM, Pastor-Vicedo JC, Contreras-Jórdan OR. Tactical knowledge and decision making in young football players (10 years old). Rev Psi Dep, 2011; 20: 79-97

Gréhaigne JF, Godbout P, Bouthier D. Performance assessment in team sports. J Teach Phys Edu, 1997; 16: 500-516

Halouani J, Chtourou H, Gabbett T, Chaouachi A, Chamari K. Small-sided games in team sports training: brief review. J Streng Cond Res, 2014; 28: 3594-3618

Hill-Haas S, Coutts A, Rowsell G, Dawson B. Variability of acute physiological responses and performance profiles of youth soccer players in small-sided games. J Sci Med Sport, 2008a; 11: 487-90

Hill-Haas S, Rowsell G, Coutts A, Dawson B. The reproducibility of physiological responses and performance profiles of youth soccer players in small-sided sames. Int J Sport Phys Perform, 2008b; 3: 393-396

Hill-Haas SV, Dawson B, Impellizzeri FM, Coutts AJ. Physiology of small-sided games training in football. Sport Med, 2011; 41: 199-220 
Hopkins W. Spreadsheets for analysis of validity and reliability. Sportscience, 2015; 19: 36-44

Hopkins WG, Marshall SW, Batterham AM, Hanin J. Progressive statistics for studies in sports medicine and exercise science. Med Sci Sport Exe, 2009; 41: 3-13

Joo $\mathrm{CH}$, Hwang-Bo K, Jee $\mathrm{H}$. Technical and physical activities of small-sided games in young korean soccer players. J Streng Cond Res, 2016; 30: 2164-2173

Kalinowski P, Bojkowski $€$, Śliwowski R. Motor and psychological predispositions for playing football. TRENDS Sport Sci, 2019; 2(26): 51-56

Katis A, Kellis E. Effects of small-sided games on physical conditioning and performance in young soccer players. J Sport Sci Med, 2009; 8: 374

Little T. Optimizing the use of soccer drills for physiological development. Streng Cond J, 2009; 31: 67-74

Müller ES, da Costa IT, Garganta J. Tactical analysis in futsal: comparative study of performance by players from four age levels. Rev Bras Cien Esp, 2018; 40: 248-256

$\mathrm{Oh} \mathrm{SH}$, Joo $\mathrm{CH}$. Comparison of technical and physical activities between 8 vs. 8 and 11 vs. 11 games in young Korean soccer players. J Exe Rehab, 2018; 14: 253

Owen AL, Wong DP, Paul D, Dellal A. Physical and technical comparisons between various-sided games within professional soccer. Int J Sport Med, 2014; 35: 286-292

Rampinini E, Impellizzeri FM, Castagna C, Abt G, Chamari K, Sassi A, Marcora SM. Factors influencing physiological responses to small-sided soccer games. J Sport Sci, 2007; 25: 659-666

Sarmento H, Clemente FM, Araújo D, Davids K, McRobert A, Figueiredo A. What performance analysts need to know about research trends in association football (2012-2016): A Systematic Review. Sport Med, 2018; 48: 799-836

Serra-Olivares J, González-Víllora S, García-López LM, Araújo D. Game based approaches' pedagogical principles: exploring task constraints in youth soccer. J Hum Kinet, 2015; 46: 251-261

Silva B, Garganta J, Santos R, Teoldo I. Comparing tactical behaviour of soccer players in 3 vs. 3 and 6 vs. 6 small-sided games. J Hum Kinet, 2014; 41: 191-202

Stevens TGA, De Ruiter CJ, Beek PJ, Savelsbergh GJP. Validity and reliability of 6-a-side small-sided game locomotor performance in assessing physical fitness in football players. J Sport Sci, 2016; 34: 527-534

Tan CWK, Chow JY, Davids K. "How does TGfU work?": examining the relationship between learning design in TGfU and a nonlinear pedagogy. Phys Edu Sport Ped, 2012; 17: 331-348

Williams AM, Hodges NJ. Practice, instruction and skill acquisition in soccer: Challenging tradition. J Sport Sci, 2005; 23: 637-650

\section{Corresponding author:}

\section{Filipe Manuel Clemente}

Complexo Desportivo e Lazer de Melgaço - Monte de Prado,

4960-320, Melgaço, Portugal

E-mail: filipe.clemente5@gmail.com 